services are delivered in a region or the potential impacts of a change to gambling laws.

Identification of the unintended potential impacts of a proposal is a particularly important aspect of HIA because of the assumption that all proposals are well intentioned and there will be few if any negative impacts from their implementation. However, this is not always the case. For example a campaign to promote healthy lifestyles, where the intent is to improve and promote people's health, may also unintentionally stigmatise those groups in the population who are unable to act on the information (for a range of reasons not within their control).

Values such as transparency, equity and community participation are generally accepted as integral to the HIA process. ${ }^{8}$ Practitioners, however, have found that the incorporation of these values can be challenging in practice (see Aldrich et al, 'Building an equity focus in health impact assessment' in this issue).

Health impact assessment is not a mandated part of the policy or program development process in any state or territory in Australia. ${ }^{6}$ However, there is increasing interest in the use of HIA as a method for improving practice and there are an increasing number of Australasian examples of its applications. As described by Harris-Roxas and Simpson in 'The NSW Health Impact Assessment Project' in this issue, in NSW there is a strong commitment to building the capacity to use HIA to improve policies, programs and projects that are developed by health and, more recently, proposals by other sectors.

\section{REFERENCES}

1. European Centre for Health Policy. Health impact assessment: Main concepts and suggested approaches. Gothenburg consensus paper. Brussels, ECHP \& World Health Organization, Regional Office for Europe: Copenhagen, 1999.

2. Mahoney M, Morgan R. Health impact assessment in Australia and New Zealand: an exploration of methodological concerns. International Journal of Health Promotion and Education 2001; VIII(1): 8-11.

3. Mahoney M. Current thinking and issues in the development of health impact assessment in Australia. NSW Public Health Bulletin, 2002; 13(7): 167-9.

4. Simpson S, Harris E, Harris-Roxas B. Health impact assessment: An introduction to the what, why and how. Health Promot J Austr, 2004; 15(2): 150-5.

5. Kemm J. Can health impact assessment fulfil the expectations it raises? Public Health 2000; 114(6): 431-3.

6. Harris E, Simpson S. NSW Health Impact Assessment Project. Phase 1 Report. Sydney: CHETRE, School of Public Health and Community Medicine, University of NSW, 2003.

7. Mahoney M, Durham G. Health impact assessment: a tool for policy development in Australia. Victoria: Faculty of Health and Behavioural Sciences, Deakin University, 2002.

8. Douglas MJ, Conway L, Gorman D, Gavin S, Hanlon P. Developing principles for health impact assessment. J Public Health, 2001; 23(2): 148-54. 용

\title{
CONTEMPORARY DEBATES IN HEALTH IMPACT ASSESSMENT: WHAT? WHY? WHEN?
}

\author{
Elizabeth Harris \\ Centre for Health Equity Training, Research \\ and Evaluation \\ University of New South Wales
}

Public health practitioners and policy makers in Australia have a long history of advocating for health impact assessment (HIA) to be undertaken on major public and private projects and policies. Over the past decade a number of internationally recognised guidelines and discussion papers have been developed in Australia that have tried to strengthen HIA in environmental impact assessment processes. ${ }^{1,2}$ Internationally, advocates for the development of healthy public policy have promoted HIA as a necessary step in policy development. ${ }^{3,45,6}$ Those with an interest in reducing health inequalities have supported this and called for a closer examination of the distributional impacts on groups within the population, especially those groups most marginalized or disadvantaged. ${ }^{7,8,9,10}$

As outlined elsewhere in this issue of the NSW Public Health Bulletin, there have now been significant investments by most Australian jurisdictions in developing HIA capacity within the health system. As these initiatives unfold there are a number of issues that need to be understood and debated within the public health community. These involve the what, why and when of HIA. This article presents those issues and Staff, in the article that follows, provides a response to each of these issues.

\section{WHAT IS HIA?}

HIA is a structured process for assessing the impacts of a proposed policy, program or project on health at the point when it has been sufficiently developed to allow likely impacts to be determined. ${ }^{11}$ HIA is therefore only one of several strategies that need to be put in place to ensure consideration of the impacts on health of what society does generally. Needs assessment, planning, monitoring and evaluation also play important roles in promoting and protecting health in the planning and development process. $^{12}$

Issue: As well as promoting HIA as an effective tool for assessing impacts on health, we also need to identify ways of building considerations of health impact earlier in the policy or project development process. 


\section{WHY DO AN HIA?}

In NSW there are no strong legislative requirements for HIAs to be undertaken, although often health impacts are considered in environmental impact assessment and social impact assessment processes. ${ }^{13}$ This leaves open the debate on the scope and function of HIA.

Is the purpose to ensure that minimum levels of safety are ensured (risk management) or is it an opportunity to maximize the extent to which health can be promoted or maintained? Depending on how this question is answered there are implications for the ways in which health is defined (a broad definition of health and well-being or a more narrow definition that is concerned with illness and death), what is accepted as evidence of an impact (rigorous scientific data as well as the perceptions of stakeholders) and the extent to which HIA becomes an expert-driven or community engagement process.

Issue: In the immediate future there is unlikely to be a consensus on why HIAs are undertaken and it will be important to match the scope of each HIA to the reasons it is being done.

\section{WHEN TO DO AN HIA?}

Because HIA is a resource intensive process it is important that it is undertaken in ways that 'value-add' to existing decision-making processes. The decision to do an HIA and at what level requires an assessment of the size and uncertainty of the potential impacts, the level of investment and the potential for the recommendations of the HIA to be acted upon. The European Commission has recently identified three levels at which HIA can be undertaken ${ }^{3}$ :

- a desk-based HIA that provides a broad overview of possible impacts and takes a single assessor two to six weeks

- a rapid HIA that provides more details of the possible health impacts and takes a single assessor about 12 weeks (this is the most frequent HIA approach)

- an in-depth or comprehensive HIA that provides a comprehensive assessment of possible impacts and takes a single assessor about six months.

Issue: In the NSW context we need to debate when an HIA should be undertaken and at what level. This debate needs to consider whether HIA is the best mechanism for reducing the potential negative and promoting the potential positive impacts of proposals.

HIA will become part of the public health armoury to improve the health of the people of NSW. We now have some experience in conducting HIAs in the NSW context and we are able to benefit from the extensive experience of other jurisdictions in Australia and internationally. Phase 3 of the NSW HIA Project ${ }^{14}$ (see Harris-Roxas and Simpson, 'The NSW Health Impact Assessment Project' in this issue) presents opportunities for a wide cross section of public health workers within health and other sectors to participate in this learning and debate. The extent to which this happens will strengthen the relevance and impact of HIA in the planning and decision-making process.

\section{REFERENCES}

1. enHealth. Health impact assessment guidelines. Canberra: National Public Health Partnership, Commonwealth Department of Health and Aged Care, 2001. Available from www.health.gov.au/internet/wcms/Publishing.nsf/Content/ health-pubhlth-publicat-document-metadata-env_impact. htm/\$FILE/env_impact.pdf.

2. National Health and Medical Research Centre. National framework for environmental and health impact assessment. Canberra: NHMRC, 1994.

3. Abrahams D et al. European policy health impact assessment. Brussels: European Commission, 2004. Available from http:// europa.eu.int/comm/health/ph_projects/2001/monitoring/ fp_monitoring_2001_a6_frep_11_en.pdf.

4. Bartlett RV. Policy and impact assessment: An introduction, Policy Studies Review 1988; 8: 73-4.

5. Mahoney M, Durham G. Health impact assessment: A tool for policy development in Australia. Melbourne: Health Impact Assessment Unit, Deakin University, 2002.

6. Signal L, Durham G. Health impact assessment in the New Zealand policy context. Social Policy Journal of New Zealand 2000; 15: 11-26.

7. Acheson D. Health inequalities impact assessment. Bulletin of the World Health Organization 2000; 78(1): 75-6.

8. Douglas MJ, Conway L, Gorman D, Gavin S and Hanlon $P$ (2001). Achieving better health through health impact assessment. Health Bulletin 2001; 59(5): 300-5. Available from www.scotland.gov.uk/deleted/health/cmobulletin/ hb595-06.asp.

9. Mahoney M, Simpson S, Harris E, Aldrich R, Stewart Williams J. Equity focused health impact assessment framework. Newcastle, Australia: Australasian Collaboration for Health Equity Impact Assessment, 2004. Available from http://chetre. med.unsw.edu.au/files/EFHIA_Framework.pdf.

10. Parry J, Scully E. Health impact assessment and the consideration of health inequalities, Journal of Public Health Medicine 2003; 25(3): 243-5.

11. European Centre for Health Policy. Gothenburg consensus paper on health impact assessment: Main concepts and suggested approach. Brussels: European Centre for Health Policy, WHO Regional Office for Europe, 1999. Available from www.euro.who.int/document/PAE/Gothenburgpaper. pdf.

12. Simpson S, Harris E, Harris-Roxas B. Health impact assessment: An introduction to the what, why and how. Health Promotion Journal of Australia 2004; 15(2): 162-7.

13. Harris E, Simpson S (2003). NSW Health Impact Assessment Project Phase 1 Report. Sydney: Centre for Health Equity Training Research and Evaluation, University of New South Wales, 2003. Available from http://chetre.med.unsw.edu. au/files/Simpson_S_(2003)_NSW_HIA_Project_Phase_1_ Report.pdf.

14. HIA connect website at http://chetre.med.unsw.edu.au/hia/ nsw_hia_project.htm. Accessed 3 November 2005. 图 